\section{A NEW METHOD OF FIXATION OF THE BONES IN EXCISION OF THE KNEE.}

\author{
BY ERNEST W. HEY GROVES, M.D., M.S. LoND., \\ F.R.C.S. ENG.,
}

ASSISTANT SURGEON TO THE BRISTOL GENERAL HOSPITAL.

IN the great majority of cases where a surgeon excises the knee-joint he aims at producing firm and immoveable union between the femur and tibia. Of course, in some cases, especially with patients of tender years and surgeons of sanguine temperament, an attempt may be made by removing the minimum of diseased tissues and by preserving the lateral ligaments to retain a moveable joint. With such cases I. am not concerned here. But apart from those instances where a deliberate attempt has been made and has failed to produce mobility, there are many where the object of absolute fixation has not been attained and in both cases the result is much the same-namely, a fibrous union in place of the joint, which is weak, painful, unsteady, and very liable to undergo flexion. So that there can be no difference of opinion about the desirability of producing absolute bony ankylosis and of avoiding fibrous union when the joint has been sacrificed. If this can be done then the patients can be told that the operation, though it will leave them with a stiff knee, yet it will be a strong and painless one, requiring no splint or appliance.

Now it is quite evident from a study of writings and textbooks on this subject that great difference of opinion exists as to the best method of obtaining absolute fixation of the bones. According to some, no special device is required at all, the raw surfaces of bones growing together without fixation. Others depend on special kinds of splints, whilst the majority find it necessary to employ periosteal stitches, silver wire, screws, nails, or pegs. It may be granted that very often these devices, or the absence of any device, produce a very good result, but in every case there is a great uncertainty, simply because not one of such methods is mechanically adequate for the purpose for which it is intended. The difficulties to be surmounted are two-fold. First, to get the cut surfaces of the bones to lie in aceurate apposition to one another; and second, to keep them there. Fven if the parts are left in good position after the operation, it is almost impossible to avoid moving them when the dressings are done; and the inadequacy of the fixation by wire, screws, or pegs results from the fact that the ends of the bone consist of soft cancellous tissue, which affords no secure hold for any of these things. And the very slightest movement of the leg when the dressings are changed will, by the great leverage used, bring a great strain on the parts.

My first illustration shows these points very clearly. It is from the case of a man, aged 37 years, who for 15 years had had pain and stiffness of the right knee. He had seen many eminent authorities in London, Edinburgh, and the provinces, but there had been so much difference of opinion about the diagnosis and treatment that he had no encouragement to submit to any one of them. But as the pain had become much worse lately he was anxious again to consider the possibility of cure. I was fortunate enough to gain his confi lence and make certain of the diagnosis by an experimental injection of 0.005 cubic centimetre of Koch's tuberculin. This sent the temperature up to $104^{\circ} \mathrm{F}$. and produced increase of heat and swelling in the joint, and excision was accordingly undertaken on May 7th, 1904. Extensive caries of all three bones of the knee-joint necessitated very free resection, about one and a half inches of the femur and three-quarters of an inch of the tibia being removed. Two three-inch screws were passed through the hollows on either side of the anterior tibial tubercle and screwed into the lower end of the femur. They held well. The immediate progress of the patient was all that could be desired. The stitches were all taken out by the fourteenth day and the temperature never rose above $99^{\circ}$. His leg was kept in a splint for six months. In the following September the skiagram which forms the illustration was taken. In spite of the two long screws there was decided mobility at the union of the bones. The screws had both moved and the head of one formed a tender swelling under the scar, and therefore both were removed under an anæsthetic. To this day the patient has to wear a leather splint round his leg without which flexion would inevitably occur.
A reference to Fig. 1 makes it clear why it is so difficult to make any kind of screw or nail hold the bones together firmly. The head and shaft of the screws have passed through the compact tissue of the shaft of the tibia, but the threads of the screws lie in the cancellous tissue of the femur. And it is impossible to make them occupy any other position. Now, cancellous tissue at the best is very friable, and when the bone has undergone the rarefying osteitis which so often accompanies disease it is quite soft. The inner screw, which lies nearer to the compact bone of the femur, is seen to have retained its position better than the outer, which lies in the middle of the bone. It is evident that in order to get a firm grip of the bone the compact tissue must be perforated in the case of both bones. Moreover, as anyone knows who has used screws for this operation, after the screw has been driven home it can still be rotated indefinitely if very little extra force be used, thus showing that the thread is not holding in the femur. So

FIG. 1.

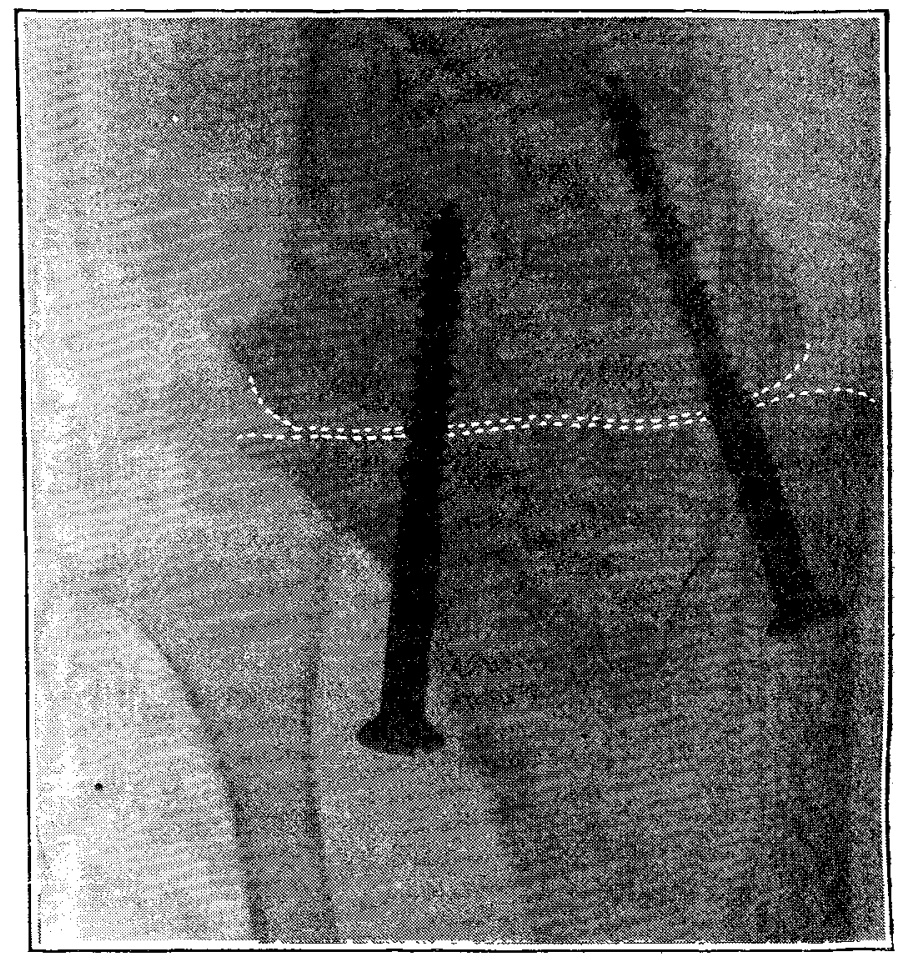

Shiagram of knee-joint six months after excision. The screws wich had been used are seen to have partly come out and the original skiagram also sbows a gap between the bone occupied by fibrous tissue and shown here by dotted lines.

that, however screws may act as pegs, they cannot be used to draw the two raw surfaces of bone tightly against one another.

It was this case which made me devise the following apparatus which gives a more adequate mechanical control over the bone ends. Two rods are passed horizontally through the femur and the tibia about two inches in each case from the line of section. Each rod is one-eighth of an inch in diameter and six inches long. The projecting ends are then drawn together by two vertical rods provided with screw threads and nuts. These can very quickly be tightened up by a box spanner. When the apparatus is in position and firmly screwed up the bones are immoveably fixed and, as a matter of fact, the whole leg can be lifted up when the femur is raised as though the bones were part of a continuous shaft. Of course, one would not put the bones to this severe test in an actual operation, but the fact can be readily demonstrated in the dead body. The final tightening of the screw-nuts can be done after all the stitches are put in and the leg is on a splint and the two surfaces of bone can be securely pressed together so that the occurrence of a fibrous zone between them is impossible. Each of the transfixing rods has a point and screw thread at one end and an eye one-eighth of an inch in diameter at the other. The lateral rods are similarly made. Each transfixing rod has one connecting rod passing through its eye and its point passes through the eye of the opposite connecting rod. The skiagram (Fig. 2) will make this clear. 
When I first used the apparatus I employed an ordinary bone drill and then pushed and screwed the transfixing rods into the hole so made in the bone, but now I have the trans. fixing rods shaped with a sharp cutting end like a bradawl and I can make the hole for the rod with the rod itself. This saves time, as it was often very difficult to find the hole made by the drill when the rod had to be passed from the soft tissues into the bone and from the bone through the soft tissues on the opposite side. The points where the trans. fixing rods pierce the skin are sealed with collodion and the whole apparatus is inclosed in dressings. The fixing rods are removed under gas at the end of a fortnight.

One more point deserves attention. In most cases the femur is diseased at a higher level between the condyles than elsewhere and the tibia is destroyed at a lower level over the tuberosities. Therefore a plane section through the farthest limit of disease in both bones will remove a good deal of healthy condyle from the femur and of sound tibia in the region of its spine. This can be avoided by cutting a kind of mortise joint shaped like

instead of a plane section of both bones. This will give a thorough removal of the diseased areas with less sacrifice in the length of the bones than the ordinary method. Further, it will afford a much larger area of contact of the raw bone surfaces and apart from the fixation apparatus will make a fibrous union almost impossible.

Fig. 2 is a skiagram of the first case in which I used this mortised-joint method. I must admit that the union shows rather bad joinery, but the man, who is 32 years old, had a very good leg with firm, bony union, not requiring a splint from the time (six weeks after the operation) he got out of bed. In this case I only used my eye to judge the lines for the mortise, but since then I have had a little

FIG. 2.

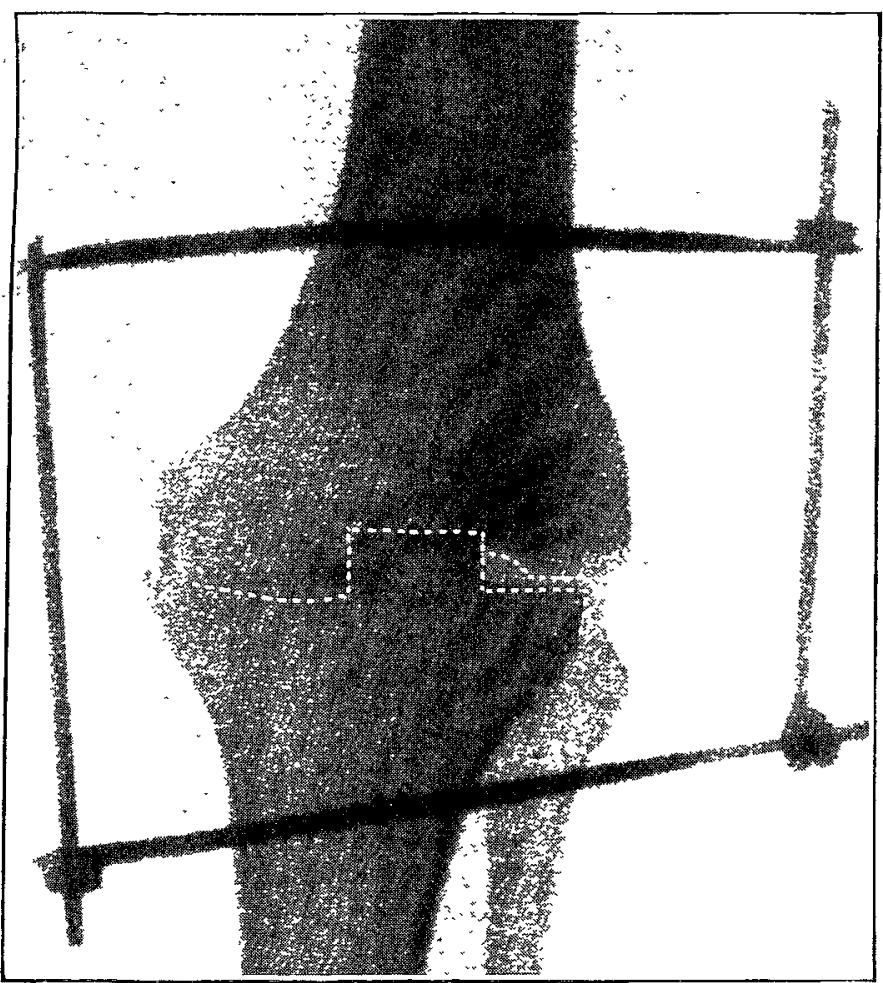

Skiagram of a knee-joint ten days after excision, the fixing apparatus being still in position. The dotted lines show the mortise joint.

tin gauge made which serves to mark out accuratèly the line of section on both bones, and Fig. 3 shows, I think, an improvement effected by this device. I have before me a skiagram of the knee of a servant girl, aged 20 years, whose joint was excised for tuberculous disease of three years' duration. The skiagram was taken three weeks after the operation after the fixation apparatus had been removed. The union of the bones is seen to be all that could be desired and there remained only one and a quarter inches shortening of the whole leg.

The apparatus has one more advantage and that is that it keeps the parts so immobile that the limb can be carefully moved from the splint without causing the patient any pain. In the ordinary method it is impossible to move the limb from the splint without causing some movement between the bones and this is a matter of great anxiety to the surgeon and of torture to the patient.

FIG. 3.

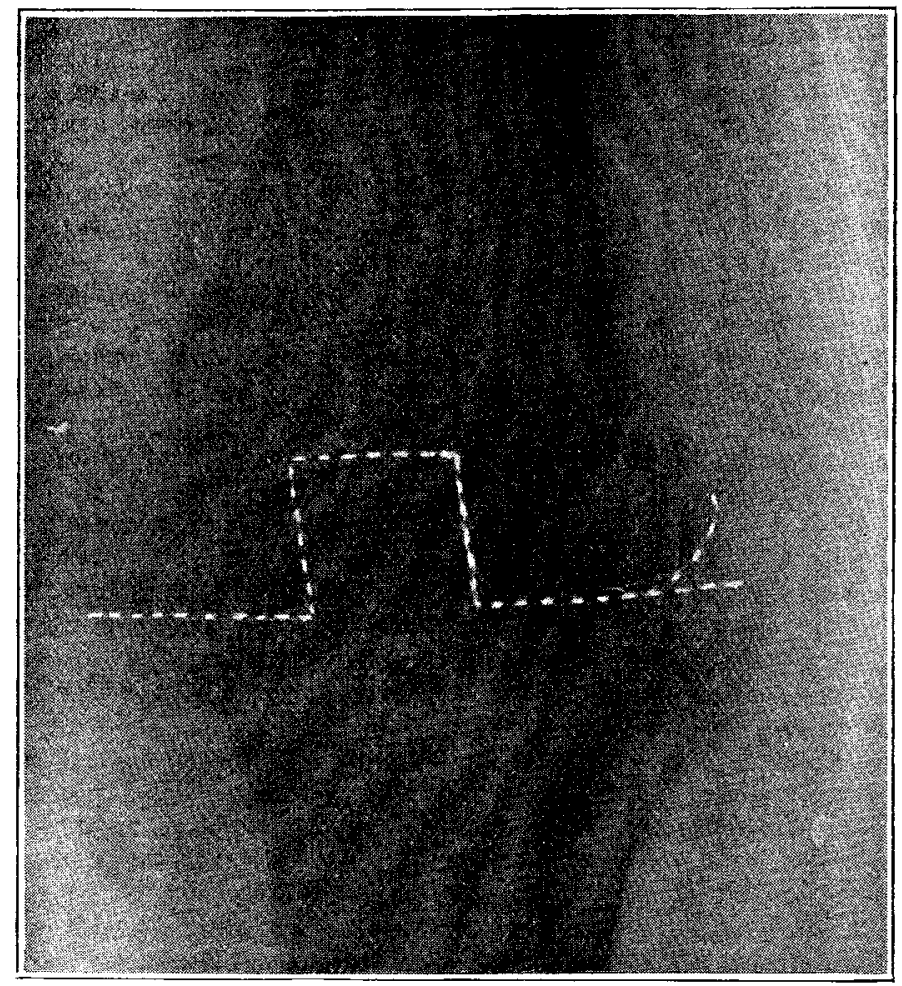

Skiagram of a knee of a girl, aged 20 years, three weeks after excision for tuberculous disease. The fixation apparatus has that the mortine joint un barly be traced and is shown by a dotted line.

In conclusion it may be fairly claimed for this operation : (1) that it fixes the bones together more firmly and more rigidly than any other method because the fixation acts upon the dense bone of the shaft and not upon the cancellous tissue; (2) that the bones are transfixed and held at points well away from the diseased area; (3) that the final fixation and tightening can be effected after the wound is sewn up and the leg is on a splint; (4) that it saves the patient a great deal of pain in the dressings ; and (5) that it leaves no foreign bodies in the bones which may have to be removed by a subsequent operation.

Clifton, Bristol.

\section{SOME AFFECTIONS OF THE PANCREAS.}

BY SIDNEY PHILLIPS, M.D. LOND., F.R.C.P. LoND., PHYSICIAT TO S'T. MARY'S HOSPITAL; SENIOR PHYSICIAN TO THE LONDON FHVER HOSPITAL.

(Concluded from p. 42.9.)

\section{III.-Acute Pancreatic Catarri.*}

ACUTE pancreatitis is divided by $\mathrm{Fitz}^{\mathrm{I}}$ into two forms, " one presenting a combination of inflammation and hæemorrhage, the more frequent termination of which is gangrene, the other is independent of hæmorrhage and is characterised rather by suppuration than by gangrene." Mayo Robson ${ }^{2}$ distinguishes three forms of acute pancreatitis: (1) acute: (2) subacute; and (3) catarrhal. He further subdivides the acute into hæmorrhagic, gangrenous, and suppurative forms ; the subacute he indicates as forming a localised abscess and the catarrhal he divides into simple catarrhal and suppurative catarrhal forms. I shall speak here only of the simple catarrhal form.

Etiology.-It is due in many cases to infection spreading along the ducts from cholelithiasis; in some cases it is set up by pancreatic calculi. But calculi are not present in all cases. I think that Mr. Robson's suggestion that catarrhal

* The tables referred to in the text were published in THE LANCET of Fob. 16th, 1907, pp. 420421.

1 Clifford Allbutt: System of Medicine, vol, iv., p. 264.

2 THe LaNCET, March 26th, 1904, p. 845. 